\title{
Yarning space: Leading literacy learning through family-school partnerships
}

\author{
Beverley Flückiger \\ Pat Diamond \\ Griffith University
}

Will Jones

C \& K Association Queensland

\begin{abstract}
EFFECTIVE PARTNERSHIPS BETWEEN PARENTS, teachers and the community have universally been heralded as crucial to improving young Indigenous Australians' participation in early childhood education and their literacy development. This study of one remote preschool setting identifies the features that successfully framed familyschool and community-led partnerships there. Our account is based on reported experiences with Parents and Learning $(\mathrm{PaL})$, a long-established program, and Mums $n$ Bubs, a recent initiative in the community preschool. Mothers said they felt empowered when equal value and respect were accorded to them as key participants in what we have described as a 'yarning space'. This was a jointly constructed space and an intercultural strategy centred on the preschool where everyone listened carefully and respectfully to each other, helping to build and lead a literacy learning community. The co-researchers were privileged to be invited into this space to hear the mothers speak with pride of their achievements.
\end{abstract}

\section{Introduction}

One of the co-researchers was a trusted friend of the preschool staff, which facilitated entry to and acceptance of the chief investigator in the research site. She encouraged and supported their sharing of personal narratives. As co-researchers, we viewed the mothers as potentially effective agents in establishing and sustaining family-school partnerships. We were invited into their 'yarning space', a safe, jointly constructed space centred on the preschool in which all voices are heard as they 'yarn up' (Burchill \& Higgins, 2005). The space was not so much a physical location as a positioning or sociocultural strategy for communicating across linguistic and cultural boundaries. In this 'third place' (Lo Bianco, Liddicoat \& Crozet, 1999), the participants were able to articulate the multiple dimensions of their own intercultural space and identity. This study of how to promote collaborative agency documents an alternative approach to traditional practices in other family-school settings where power and control rest firmly with the school and its agents and remain unchallenged. We then used a narrative case study to contest the power and control of research traditions that, like some school or project leaders, only talk or 'yarn down' (Burchill \& Higgins, 2005) to their community members.
We also write in part from the first-person point of view to take advantage of the developmental opportunities that such autobiographical writing affords all participants (Pinar \& Grumet, 1976). (Auto)biographical research is a powerful and effective way to study knowledge formation and to understand (pre)schooling (Pinar, Reynolds, Slattery \& Taubman, 1995). Using such a personal knowledge approach helps prevent projects or programs being misunderstood as uni-dimensionalas bodies of knowledge or 'right ways' to be applied generally.

In late 2009 we commenced this study at the community preschool in Napranum, an Aboriginal Community on Western Cape York in remote far north Queensland. We were keen to identify the nature of the family-school and community partnership that seemingly underpinned the success of its longestablished Parents and Learning (PaL) program and a recent initiative, Mums $n$ Bubs. The aim of both these programs is to engage parents as partners with the preschool in their children's literacy learning.

PaL was designed in 2001 as a bespoke literacy program to support parents in Napranum as they sought to engage in their child's literacy learning. Initially, Aboriginal and Torres Strait Islander representative parents and the preschool teacher/director considered implementing 
the Israeli-developed Home Interaction Program for Parents and Youngsters (HIPPY) but it was considered unsuitable for Napranum parents and children. The parents and teacher/director instead created their own program, using literature that supported community beliefs and values. They developed a series of kits that consist of a book and accompanying literacy activities for parents to undertake with their children. Tutors are trained to visit homes to deliver the kits, explain the literacy activities, and liaise with parents. $P a L$ is now run by a board of Aboriginal and Torres Strait Islander parents and employs a program manager, coordinator, and local community tutors. Until recently, PaL was funded by international mining company Rio Tinto, a company that mined bauxite nearby. Now it relies on philanthropic or government funding to implement the program.

The Mums n Bubs program is a more recent initiative. Mothers are encouraged to come to the preschool with their babies and toddlers each week to enjoy social time together. The mothers themselves plan a program of activities which the preschool director and $\mathrm{PaL}$ tutors facilitate. Activities may consist of sharing the skills of individual members such as art, scrapbooking, and jewellery-making. They also include information sessions on a range of topics of interest or focus on practical skill development, such as preparing to gain a driver's licence.

It is acknowledged that children do better in school when parents are engaged in their learning (Henderson, Jacob, Kernan-Schloss \& Raimondo, 2004). Both the PaL and Mums n Bubs programs seek to enact the central belief of DEEWR (2008) that sustaining effective partnerships between parents and teachers is crucial to improving Indigenous children's literacy performance, their attendance and participation at school. However, there is a paucity of research on examples/benefits of Indigenous parent involvement in Australia (Daniel, 2005), and the need to remedy this situation is urgent.

Aboriginal and Torres Strait Islander children, particularly those in remote areas, consistently perform below the national average in literacy. Results in the National Assessment Program Literacy and Numeracy (NAPLAN) indicate that the majority of Aboriginal and Torres Strait Islander students in very remote Australia currently do not meet the national minimum standard in reading and writing, and that literacy skills decrease as the level of remoteness increases (FaHCSIA, 2010; MCEETYA, 2008). These children are likely to lag behind non-Indigenous children from their very first year of formal schooling, creating barriers that prevent them achieving their full potential and perpetuate their level of disadvantage in living standards, life-expectancy, education, health and employment (Australian Government, 2009).
Participation in early childhood education programs has been identified as a way to enhance literacy skills, and has been found to be more cost-effective than intervention at later ages (Elliott, 2006; Frigo \& Adams, 2002; Heckman, 2006). However, three- to five-yearold Aboriginal and Torres Strait Islander children in very remote areas are far less likely to attend preschool than are those living in other areas of Australia (Australian Government, 2009; Biddle, 2007). While the Australian Government is committed to the provision of universal access to early childhood education by 2014, attendance of Aboriginal and Torres Strait Islander children in educational programs clearly remains a major issue (Banks, 2009).

Hattie (2003) identified two of the most critical factors that contribute to such disparities in children's learning and development. These involve the attitudes, values, behaviours and other attributes children bring to their learning, along with family levels of expectation and encouragement. Therefore, establishing shared aims and goals, and developing common understandings about literacy learning specifically, and education generally, amongst families, schools and their communities from the earliest stage of a child's development is seen as crucial to increasing the participation of Indigenous children in preschool, and in later schooling (DEEWR, 2008).

Daniel (2005) articulated the need for research to investigate the outcomes of a range of involvement practices, including those in Indigenous Communities. Research is reconceptualised in the present study to take account of the informal stories and conversations (the 'yarning') of the participants and the researchers by adopting a narrative inquiry approach. According to Clandinin and Connelly (2000), narrative inquiry involves an understanding of 'narrative as both phenomena under study and method of study' (p. 3). It seeks to inquire into the ways people make meaning of their lives as narratives or 'yarning'.

Richardson (1997) described the challenge that confronts researchers when their inquiries take a narrative turn:

We are restrained and limited by the kinds of cultural stories available to us. Academics are given the 'story line' that the ' $I$ ' should be suppressed in their writing, that they should accept homogenization and adopt the all-knowing, all-powerful voice of the academy. But contemporary philosophical thought raises problems that exceed and undermine the academic story line. We are always present in our texts, no matter how we try to suppress ourselves (p. 2).

Similarly, Aboriginal and Torres Strait Islander children and their parents have for too long been given the 'story line' that 'they' must remain unheard and suppressed at the margins of schooling, unable even to voice their ' $w e$ '. 


\section{Participants and setting}

The Napranum preschool is situated in a dry (alcoholfree) Aboriginal community near the mining town of Weipa on the remote western side of Cape York in far north Queensland. It was chosen for the study because it has enjoyed prominence for its success in engaging parents in literacy activities with their children through its PaL program (DKCRC, 2009). As explained above, one of the co-researchers was a trusted friend of the preschool staff, which facilitated acceptance of the chief investigator and encouraged the sharing of personal narratives or local knowledge.

The preschool is affiliated with C\&K (a provider of community not-for-profit early childhood education and care services in Queensland) and supported by the Napranum Aboriginal Shire Council. It caters for approximately 65 children, most of whom are Aboriginal but also include a proportion of Torres Strait Islanders, in three rooms: Alandahk (barramundi) for children aged 3-31/2 years; Keymbal (crocodile) for 31/2-41/2-year-olds; and Thungghan (flying fish) for $41 / 2-51 / 2-$ year-olds. The staff consists of local Aboriginal women, with the exception of the teacher/director who is of Torres Strait Islander/ European heritage (hence considered an outsider), and a teacher of European heritage (also an outsider) who lived in Weipa and travelled to Napranum each day.

The main participants in the study were the current classroom teachers (including the teacher/director) $(n=3)$, teacher aides $(n=3)$, parents $(n=5)$ of children currently attending the preschool, past parents $(n=6)$ who are tutors and coordinators of the $P a L$ program, and the program manager (a past teacher and co-developer of PaL). Conversations with three representatives of the broader community who attended the preschool end-of-year function also contributed indirectly to the researcher's construction of how family-school partnerships were co-constructed. The participants (a grand total of 20) were willing for the preschool and its programs to be identified. Pseudonyms have been used for parents.

\section{Method}

A combined qualitative approach, using narrative inquiry, portraiture (Lawrence-Lightfoot, 1997), and case study (Yin, 2006) methods, was chosen as we wished to illuminate a particular situation (Napranum), and to provide a close (in-depth and first-hand) understanding of how its home-school and community viewed the learning partnership.

We had no preferred explanation for what contributed to the positive home-school and community partnership at Napranum preschool but were empathetic to the participants. We were intent on discovering the relationships and underlying concepts that characterised their yarning space, while gaining an understanding of the phenomenon of leading literacy learning (Strauss \& Corbin, 1998), and honouring their stories as we took them to where they could be heard by all. In this research account, features of the PaL program and activities in the Mums $n$ Bubs program are used to illustrate how partnerships connected to leading the children's literacy learning were built.

\section{Storied data collection}

The data was collected over several weeks at the end of the preschool year, using direct observation, field notes, interviews and document reviews. Informal conversations (yarning) replaced interviews as the primary way in which understandings were solicited. Yarning has been described as 'a transactional activity that involves negotiation and trust' (Imtoual, Kameniar \& Bradley, 2009, p. 27). The conversations focused on involvement in the preschool; the operation of programs and activities; home reading; and roles and relationships of teachers, parents and the community. Observations and field notes were taken of interactions in the preschool, on the bus trips to collect and deliver children, and during the end-of-year party and graduation ceremony. Documents generated in relation to the $\mathrm{PaL}$ program were also examined. These included an evaluation of PaL at Napranum (Makin, $2003,2005)$ and a 2009 report by the Desert Knowledge Cooperative Research Centre.

\section{Data analysis}

The data was analysed using a content analysis process similar to that used in grounded theory method (Charmaz, 2002) and in narrative inquiry. First, recordings of the yarning sessions were transcribed and read repeatedly in conjunction with the observation field notes to identify 'bites' of information considered important. A code was assigned to each bite and then codes were compared to find consistencies in order to develop categories and identify themes. We did not try to make the data fit any preconceived themes (Trace, 2001). Throughout this paper, selected extracts from the participants are cited to illustrate the four main themes that emerged. To honour the owners of the stories and their portraits (see Pearl and Catherine below) a draft of this paper was sent to the participants for comment, and changes were made in response. This membership checking helped to corroborate our main findings.

\section{Findings}

Typically, schools have been responsible for initiating the development of family-school partnerships with a focus on school learning and school agendas (Cairney, 
2000). In these instances of 'yarning down', power and control reside firmly with the school and its agents, where they remain unchallenged. Many barriers (issues of class, ethnicity, gender, aboriginality and culture) have previously been identified that discourage families from minority, marginalised and disadvantaged groups being involved in these partnerships (Daniel, 2005). There are few reported cases where genuine, reciprocal partnerships have been established between home, school and communities. However, the Napranum community preschool with its co-constructed 'yarning space' provides a rare exception.

\section{The nature of family-school relationships at Napranum}

The relationship established between families and the preschool staff is based on trust and mutual respect. Parents interviewed for this study felt they were welcome in the preschool and felt comfortable there. Pearl, a grandmother who is parenting her grandchild, regularly assists in the preschool and introduces her Torres Strait Island culture to the children through music and songs. Similarly, Catherine, a young Aboriginal mother with a blended family of her own children and those of her brother, likes to spend time in classrooms because 'They're [the staff] friendly towards the parents and the kids. The way I see it is that I can trust them because they're really good with kids. They're not angry and they don't talk rough or down with them'.

Most parents, however, do not participate in the classroom. As one teacher of European heritage observed, 'The parents trust her [the teacher/director] enough to leave the teaching to her, which seems to be what happens here'. The trust appears mutual. A teacher aide remarked: 'When we need the parents, they will come'. The teacher/director explained that trust is established through personal connections and links to the community: 'So long as you know someone, so long as you have that connection, that personal connection, everything's going to work out fine'. She went on to give an example:

When we growl [at] these parents and say, like, I tell them that one in three black kids will fail a basic literacy, numeracy test in Grade 3. Our children are failing. Don't say they're not because they are. We have [a] high percentage of our mob in jail. A high percentage of our kids walk around here sniffing, pushing prams, nine years [old] with STDs. I said this is not something we made up so do not go and blame anybody else, because the rent's high and this, but yourself. And we can say that because we were in the same situation ...

Lack of apparent participation by many parents does not mean that they are not interested in their children's education. As one parent remarked about the progress of her little boy:

I took notice of the way, how he speaks. He's speaking, like, really good, speaking out there, using big words, different words. I find that, I'm very proud of that, like what the teacher's done and all the others. I'm very proud of that. That's why I come and give my time to the preschool.

\section{Issues of power and leadership}

Despite setbacks such as the closure of the primary school, there is a growing belief among some of the mothers in the community that they can initiate change and take up leadership roles. A group of parents shared their story of the 'sorry business' within the community over the State Government's authorised closure of the primary school in Napranum in 2007. The primary school was described as '... part of our history path. It was the spirit of the community' and a safe meeting place for mothers. Shutting it down meant that young children would need to catch the bus to Weipa to attend Prep. Parents and staff expressed a sense of loss and grief. In the words of one mother: 'The community is still angry and grieving over the way we were treated in not being consulted in the decision-making process. It was decided to close the school before we were told. Parents felt powerless'. In the words of another: 'People [bureaucrats] don't listen to our voices. They just listen to what is on paper. [They think] word isn't truth. [They think] writing is truth'. In what is traditionally an oral community, there was a sense that the written word was valued over the spoken word. However, the preschool teacher/director, a member of the community (though an outsider), was not defeated. A tireless intermediary, she arranged a meeting with the educational authorities explaining:

I'm always going to stand up. And it helps when you've got the support of your family and your colleagues and your community. It does help. If we come as a united voice for the voice of our children, people are going to listen to us. And that's what we did when we wanted to keep the Prep room open. We got our mums together, we got reinforcements and bang, that day, we're the only kindergarten in the state that offers Prep.

Her role as leader in the community, however, is not without boundaries. She commented, 'I'll help on things educational and be their advocate because they've asked me to, but I know better than to poke my nose into things that I haven't been asked to poke my nose into'. In many ways her leadership role is one of service. She supports parents with the demands placed on them by a literate community. For example: 
I help them with their blue card ... helped them with their resume, doing stat decs [statutory declarations], taking them to the court house to fill in birth certificates. - Ain't my job. I don't get paid to do that but you just do it.

Preschool parents have also taken on leadership roles within the preschool community. Pearl acts as an agent in getting children to attend preschool:

If I went past and I see other kids sitting on the step, and they are ready to go to school, I sort of, I got the authority to bring her up because I'm involved in the school and they [the parents] know that you know.

Catherine has also become an activist for the preschool. She commented:

Sometimes when I go out I tell parents that, you know, 'Go down to the school and if youse (sic) really want to know what your children do. Go and see. Like, they've got books like that. What they do, they show you, and they break things down in their own ways so that you can understand.'

These examples of advocacy come as no surprise given that there is quite a history of strong women in Napranum demonstrating leadership in education. In 1967 one mother (name withheld to respect the deceased) in the community established the kindergarten in Napranum and became its first preschool teacher.

\section{'Yarning up' as exercising agency and voice}

In 2001 a small group of Aboriginal and Torres Strait Islander mothers approached the non-Indigenous preschool teacher/director, seeking support for them to assist in their children's literacy development. These mothers demonstrated the importance they placed on promoting literacy in their children's lives.

It is the somewhat unexpected courage of these women in stepping forward to assist their children to learn to be literate in standard Australian English, and their belief in their own capacity to learn, that make their actions remarkable-especially in a community that speaks Torres Strait Islander Creole and Aboriginal English (referred to as Broken English). Kral (2009) maintained that, in comparison to most Western or other major literate cultures, Aboriginal and Torres Strait Islander people in the remote world have made the transition from an oral to a literate culture only relatively recently. They are pioneers in social literacy practices. She reminds us that literacy in English has taken more than 1,000 years to evolve and, if the current generation of Aboriginal and Torres Strait Islander children are to acquire a set of literate cultural practices in our lifetime, then literacy needs to be incorporated into the fabric of their life beyond the school.
The teacher/director responded to the mothers' request by providing further opportunity for them to be involved. She engaged them to work with her in the development of $P a L$, describing her role as: 'I see myself as part of a team. As a teacher, I am a guest in their community. You have to fit in with the rhythm of the community'.

The mothers investigated other literacy programs but found them unsuitable. In the words of one coordinator, ' $P a L$ is a success because we knew the Hippy Program wouldn't work ... I said our children are not going to understand that ... we need to do our own. And we did it our way, you know'. Another remarked, 'We made the game. We took it, tested [it] with our kids. We're sitting there and writing things down and saying, "Oh, we should change it this way, this way and that." And then we went back [to the preschool] and said, "Okay. This is the game. This is how you're going to play the game because this is how the kids played it".' Similar opportunities for parents to exercise agency and develop their feelings of self-efficacy (belief in their own competence) are evident in the continual development and expansion of the activities in the PaL program.

Mums $n$ Bubs is another program designed for mothers to exercise their voice in an educational setting and where opportunities to develop self-efficacy are provided. In the words of one tutor who does not 'yarn down', 'We want Mums to feel good about themselves'. The current teacher/director explained further, 'They have to come out of their safety zone at home and they have to engage in a professional educational setting where people do work and they can see us as working and this is not just a home thing ... We set this up to show mothers what they can do, not what they should do, what they can do'.

One mother who regularly attends Mums n Bubs said: 'I find that [Mums $n$ Bubs] really good, like, because it helps. It helps other parents to come forward. It helps them how to read and how to connect to their kids'.

\section{'Yarning up' as promoting empowerment}

We saw the mothers' involvement with $P a L$ as having an empowering effect as they grew more confident about speaking up. One of the first parents to be involved in $\mathrm{PaL}$ now has a Bachelor of Education degree and is the current teacher/director of the preschool. Another past parent who is now the coordinator of $P a L$ was described by another mother:

From doing PaL she's more confident in speaking, like, she goes and addresses all these people. I went with them to Melbourne. We went with [sic] a big conference they had, from all over the world. She's got her driver's licence. She's got a steady income. Now, she's flying halfway around Australia, 
all these places that I've never been ... She's planning to start a business with her partner. I think it's earthmoving.

A third past parent described her own involvement in the $P a L$ program and its powerful effects on her:

Yeah, it started, because I was a parent and after my daughter finished her two years and someone asked me if I wanted to be a tutor so it just went from then, like we became a tutor from a parent and took on six families, went out into the community once or twice a week and then moved onto being a coordinator ... And it's just like a stepping stone for the parents I suppose. All of the parents that have come through as tutors have moved on to bigger and better things. We can't sort of hold the parents back for maybe not even a year because they just moved on to other things. I think PaL has been an instrument. I think it builds their self-esteem in more ways than one. I suppose just going out and talking to people gives them a bit of courage to maybe go up and look for jobs, because I know some of these parents. You go to do your weekly visits and they'd hardly say two words to you, now they've gone on to full-time jobs, driving trucks with Rio Tinto and you think 'Oh, you know that's a big step because yeah, I'd like to think PaL had a hand in that'.

\section{Discussion}

In many family-school interactions, the strengths of Aboriginal and Torres Strait Islander parents and their communities are often overlooked or undervalued by inappropriate interventions and by inexperienced but well-intentioned practitioners (Shepherd \& Walker, 2008). In many instances practices have been imposed within 'a broadly paternalistic framework, assuming the superiority of mainstream views' (Priest, King, Nangala, Brown \& Nangala (2008, p. 123). The experiences of the staff and parents at Napranum preschool, characterised by trust and a mutual respect, suggest that an alternative model is possible.

The approach to family-school partnership building at Napranum preschool, with examples taken from its PaL and Mums n Bubs programs, has demonstrated that genuine collaboration and leadership can occur in a space where leadership, power and responsibility are shared. The approach has resulted in 'power to' rather than 'power over' (Stone, Doherty, Jones \& Ross, 1999, p. 354).

Smyth (2009, p. 14) described approaches that focus on 'building power that results in social justice' in school contexts as 'community organizing'. The following principles (Makuwira, 2007) inform community organising: participation-seen as an end in itself through knowledge-building and being responsible custodians: inclusiveness_drawing diverse communities into the decision-making processes, especially those at the periphery of decision making; scope of mission and vision-clear and precise aims and goals that embrace broader issues affecting the community rather than being narrowly focused; and critical perspective -advocating positive policy and institutional change conducive to active participation, ownership, accountability and transparency in organisations and institutions that marginalise people (pp. 383-384).

We hope this beginning study will encourage other leaders to learn to encourage parents to 'yarn upwards' and so challenge the existing power structures in schools and to seek ways to emancipate both leaders and followers. As researchers, we were often humbled by the wisdom of the mothers and inspired by their stories of survival and hope. We learned to appreciate their points of view and stories simply for what they were and to resist appropriating or smoothing them for our own ends.

\section{Conclusion}

A yarning space can provide a culturally safe, appropriate and effective solution to meet the literacy needs of an Indigenous community. 'Yarning up' relates to 'yarning for outcomes' rather than speaking down to Aboriginal and Torres Strait Islander peoples. 'Yarning down' is an indication that an outsider, advocating some 'fly-in, fly-out' service model, knows best or has taken control of the outcomes for Indigenous people. Well-meaning school leaders often set out to 'fix the problems' within Aboriginal and Torres Strait Islander communities instead of supporting a space where meaningful engagement and reciprocity can occur. Such a space can have an empowering effect, as exemplified in the words of one Napranum mother: 'It wasn't somebody, some white person outside saying "you need to be doing this because it will be good for your kids". It was Napranum parents saying "this is what we want for our kids".'

\section{References}

Australian Government (2009). Closing the gap on Indigenous disadvantage: The challenge for Australia. Canberra: Author.

Banks, G. (2009). Are we overcoming Indigenous disadvantage? Presented as the third lecture in Reconciliation Australia's 'Closing the Gap Conversations' Series, National Library, Canberra, 7 July 2009.

Biddle, N. (2007). Indigenous Australians and preschool education: Who is attending? Australian Journal of Early Childhood 32(3), 9-16.

Burchill, M., \& Higgins, D. (2005). Indigenous community development. Australian Institute of Family Studies. Retrieved 13th May, 2012, from: http://www.aifs.gov.au/nch/pubs/2005/ reports/telstra\%20v.2.pdf. 
Cairney, T. (2000). Beyond the classroom walls: The rediscovery of the family and community as partners in education. Educational Review, 52(2), 163-174.

Charmaz, K. (2002). Qualitative interviewing and grounded theory analysis. In J. F. Gubrium \& J. A. Holstein (Eds), Handbook of interview research: Context and method (pp. 675-694). Thousand Oaks, CA: Sage Publications.

Clandinin, D. J., \& Connelly, M. F. (2000). Narrative Inquiry: Experience and Story in Qualitative Research. San Francisco: Jossey-Bass.

Daniel, G. R. (2005). Parent involvement in children's education: Implications of a new parent involvement framework for teacher education in Australia. Proceedings of the Australian Teacher Education Association Conference 2005, Teacher education: Local and global (pp. 144-148). Surfers Paradise: Griffith University.

Department of Education, Employment and Workplace Relations (DEEWR) (2008). Family school partnerships framework: A guide for schools and families. Canberra: Author.

Desert Knowledge Cooperative Research Centre (DKCRC) (2009). An evaluation of the Parents and Learning (PaL) program in the Napranum Community. A report to the Napranum Preschool Pal Group Ltd and Rio Tinto by the DKCRC, Alice Springs, Australia.

Elliott, A. (2006). Rethinking and reshaping early childhood care and education policy: Visions and directions for the future. Australian Council for Educational Research, National Education Forum Conference, 2006, Brisbane.

Department of Families, Housing, Community Services and Indigenous Affairs (FaHCSIA) (2010). Closing the gap: Prime Minister's report 2010. Canberra: Author.

Frigo, T., Corrigan, M., Adams, I., Hughes, P., Stephens, M., \& Woods, D. (2004). Supporting English literacy and numeracy learning for Indigenous students in the early years. ACER Research Monograph 57. Camberwell, Victoria: ACER.

Hattie, J. (2003). Teachers make a difference: What is the research evidence? Australian Council for Educational Research, Melbourne. (Paper given at Building Teacher Quality Conference October 2003). Retrieved 13th May, 2012, from http://www.visionschools.co.nz/assets/documents/john_ hattie.PDF.

Heckman, J. (2006). Skill formation and the economics of investing in disadvantaged children. Science, 312, 1900-1902.

Henderson, A., Jacob, B., Kernan-Schloss, A., \& Raimondo, B. (2004). The case for parent leadership. Prichard Committee for Academic Excellence.

Imtoual, A., Kameniar, B., \& Bradley, D. (2009). Bottling the good stuff: Stories of hospitality and yarnin' in a multi-racial kindergarten. Australasian Journal of Early Childhood, 34(2), 24-30.

Kral, I. (2009). The literacy question in remote Indigenous Australia. CAEPR (Centre for Aboriginal Economic Policy Research) Topical Issue No 6/2009.

Lawrence-Lightfoot, S. (1997). A view of the whole: Origins and purposes. In S. Lawrence-Lightfoot \& J. H. Davis, The art and science of portraiture (pp. 1-16). San Francisco, CA: Jossey-Bass.

Lincoln, Y., \& Guba, E. (1985). Naturalistic inquiry. Newbury Park, CA: Sage.

Lo Bianco, J., Liddicoat, A., \& Crozet, C. (1999). Striving for the third place: Intercultural competence through language education. Melbourne: Language Australia.
Makin, L. (2003). Parents and Learning (PaL) at Napranum: A process and outcomes evaluation. (Unpublished report).

Makin, L. (2005). Parents and Learning (PaL) at Napranum: Follow-up evaluation. Unpublished report.

Makuwira, J. (2007). Community organizing. In G. Anderson, \& K. Herr (Eds), Encyclopedia of activism and social justice, Vols. 1, 2 \& 3 (pp.383-385). Thousand Oaks, CA: Sage Publications.

Ministerial Council on Education, Employment, Training and Youth Affairs (MCEETYA) (2008). 2008 National Assessment Program Literacy and Numeracy. Canberra: Author.

Macgregor, R. (2005). Exploring the dynamics of effective and innovative family-school and community partnerships across Australia. A paper presented to the European Research Network About Parents in Education Conference in Oviedo, Spain on 16 September 2005.

Pinar, W. F. (2004). What is curriculum theory? In W. F. Pinar \& M. R. Grumet (Eds), Towards a poor curriculum. Dubuque, IA: Kendall/Hunt.

Pinar, W. \& Grumet, M. (1976). Towards a poor curriculum. Dubuque, IA: Kendall/ Hunt.

Pinar, W. F., Reynolds, W., Slattery, P., \& Taubman, P. (1995). Understanding curriculum: An introduction to the study of historical and contemporary curriculum discourses. New York: Peter Lang.

Priest, K., King, S., Nangala, I., Brown, W., \& Nangala, M. (2008). Warrki Jarrinjaku 'working together and everyone listening': Growing together as leaders for Aboriginal children in remote central Australia. European Early Childhood Education Research Journal, 16(1), 117-130.

Richardson, L. (1997). Fields of play: Constructing an academic life. New Brunswick, NJ: Rutgers University Press.

Shepherd, C., \& Walker, R. (2008). Engaging Indigenous families in preparing children for school. Evidence into Action Topical Paper. Australian Research Alliance for Children \& Youth. Retrieved 13th May, 2012, from www.aracy.org.au.

Smyth, J. (2009). Critically engaged community capacity building and the 'community organizing approach' in disadvantaged contexts. Critical Studies in Education, 50(1), 9-22.

Stone, C., Doherty, K., Jones, C., \& Ross, T. (1999). Schools in disadvantaged neighborhoods: The community development challenge. In R. Ferguson \& W. Dickens (Eds), Urban problems and community development (pp. 339-380). Washington, DC: Brookings Institution Press.

Strauss, A., \& Corbin, J. (1998). Basics of qualitative research: Techniques and procedures for developing grounded theory (2nd edn). Thousand Oaks, CA: Sage Publications.

Taylor, R. (2003). An indigenous perspective on evaluations in the inter-cultural context: How far can one throw a Moree boomerang? Evaluation Journal of Australasia, 3(2), 44-52.

Trace, C. (2001). Applying content analysis to case study data: A preliminary report. InterPARES project. Los Angeles: University of California.

Yin, R. (2006). Case study methods. In J. Green, G. Camilli \& P. Elmore (Eds), Handbook of complementary methods for research in education (3rd edn). Majwah NJ: Lawrence Erlbaum Associates. 